\title{
Improving the Textbook Adoption Process in Taiwan
}

\author{
Hsuan-fu Ho (Corresponding Author) \\ Assistant Professor, Graduate Institute of Educational Administration and Policy Development \\ National Chiayi University, 85 Wenlong Minshong, Chiayi County, Taiwan 62103 \\ E-mail: hfho@mail.ncyu.edu.tw \\ Ying-tsun Hsu \\ Master student, Graduate Institute of Educational Administration and Policy Development \\ National Chiayi University, 85 Wenlong Minshong, Chiayi County, Taiwan 62103 \\ E-mail: Garfield9_17@hotmail.com
}

Received: March 8, 2011 Accepted: March, 15, 2011 Published: November 1, 2011

doi:10.5539/ies.v4n4p92 URL: http://dx.doi.org/10.5539/ies.v4n4p92

\begin{abstract}
Textbooks were centrally selected in Taiwan until 1996 when the government commissioned its Textbook Liberalization Reform. Although this policy received complements from scholars and the general public, it encounters many unexpected problems in its implementation. The aims of this research are thus to identify the major criteria used by elementary school teachers for textbook selection, to calculate the relative weights of the criteria, and to map the relative market positions of the major textbook publishers. Survey questionnaires were administered to 504 elementary school teachers. AHP, ANOVA, and correspondence analysis were adopted for analyses. The results show that accuracy of content and instruction methodologies are the two most emphasized criteria. Moreover, teachers of different backgrounds rank the criteria differently. Suggestions are given to teachers and textbook publishers for improving the textbook selection process in Taiwan.
\end{abstract}

Keywords: Textbook, Positioning, School, Marketing, AHP, Correspondence analysis

\section{Introduction}

For more than 30 years textbooks for the elementary and secondary education levels in Taiwan were centrally planned, standardized and distributed by the Ministry of Education (MOE) of Taiwan. Then, in 1996, the government abruptly commissioned its Textbook Liberalization Reform. In addition to opening up textbook production to private publishers, this reform also transferred textbook selection authority to individual schools.

Tully and Farr (1990) argue that the transference of textbook selection authority to local schools will encourage teachers and administrators to become more engaged in the selection of their instructional materials and to analyze the texts more thoroughly and comprehensively. This, in turn, accelerates their professional development. Their position is supported by many Taiwanese scholars. Zhao (1994), for example, claims that the textbook liberalization approach will not only encourage the professional development of school teachers, but will also enrich the content of textbooks per se in the long run. Lan (2001), as another example, asserts that letting teachers select their own textbooks ensures that the texts more closely align with the needs of the students and community culture, and since the contents of the textbooks are more familiar and meaningful to students, their comprehension and willingness to learn both increase.

Although the textbook liberalization policy received many compliments from scholars and the general public in Taiwan, this educational reform encountered many unexpected problems in its implementation. Such problems include insufficient time allocated to textbook adoption; teachers without adequate ability to select texts; publishers offering incentives and trinkets to teachers in return for adopting their textbooks; content fallaciously being announced by publishers as research-based; and parents not wanting their kids to be used as guinea pigs. Of all of these, the most significant problem identified by scholars is the lack of knowledge and training on the part of teachers serving on textbook selection committees, and therefore, offering teacher training and technical support (e.g., guidelines and criteria checklists) is crucial to the improvement of the textbook selection process (Deng, 2003). 
Today, there are three largest publishing groups that produce textbooks for Taiwan's elementary school market: PA, $\mathrm{PB}$, and PC (pseudonyms), each of which has its own strengths and weaknesses in the textbook market. Even though the number of publishers has declined significantly, the competition amongst the remaining publishers is as fierce as ever, and publishers have adopted an array of marketing strategies and campaigns to improve their sales. Sales representatives regularly provide schools with trial copies of their textbooks, teacher manuals and ancillary materials. Some publishers may even offer dinners or trinkets to school teachers, provide discounts on list prices, arrange free teacher in-service training, etc., all in hopes of enhancing their position in the selection process.

For the sake of long-term benefits, it is necessary for the publishers not only to offer all these free or discounted services, but to better understand the needs of their target market so that they can design their products and marketing strategies to better align with school curriculum objectives and teacher expectations. Thus a weighting of the criteria as perceived by teachers would be of great value to publishers. Hence, by integrating Analytic Hierarchy Process (AHP) and correspondence analysis, this research aims to uncover the relative importance attached to the criteria used for textbook selection by teachers, and generate positioning maps for publishers in respect to those criteria and teaching subjects.

\section{Related Literature}

Textbooks is the key to curriculum development and implementation through dissemination to teachers and students, and therefore, textbook adoption process is one of the major ways curriculum content is changed (Reynolds, 1979). Since textbooks serve as the basis for 75 to 90 percent of classroom instruction, and once selected, textbooks will typically continue to be used in the school for many years, an inappropriate selection can cause great harm to students, schools, and education as a whole (Shannon, 1982).

However, weaknesses in the adoption process are identified. Farr, Tulley and Powell, (1987) and Stein, Stuen, Carnine, and Long (2001) argue that the most significant three shortcomings are: Most educators do not possess the knowledge or pedagogical expertise necessary to assess the textbook; A shortage of time to review all the textbooks; and the lack of research-based criteria for evaluating textbooks. In addition, Alter (2001) lamented that educators usually support the use of standardized textbooks because they believe that there is no better choice, and this has attributed to the monopoly of publishers on textbooks, which in turn further limit the choice for textbook selection.

Over the years, scholars and the government have offered an abundant array of textbook selection checklists and criteria in an effort to address this lack of ability in textbook selection amongst teachers. Although many teachers complain that no general list of criteria or checklists can be applied to all teaching and learning contexts, advocates of the effort claim that standardized criteria or guidelines contain similar components, and, although they may not be perfectly applicable to all situations, they can still be used to help teachers in a wide variety of situations (Oh, 1996; Lai, 1996).

Oh (1996) suggests that to make the best possible selection, teachers should thoroughly evaluate potential textbooks based on the following four criteria:

i. Publisher criterion: it is important to know that the publisher is reliable. Teachers have to check the publisher's general reputation, and also have to know whether the authors of the textbook have a strong professional standing in their respective fields. Moreover, textbook cost has imposed a financial burden on parents, and thus it is important for teachers to carefully consider a textbook's affordability. Other important factors that should be incorporated in this criterion are a publisher's logistic capability, distribution system, and customer services.

ii. Physical features criterion: Textbook evaluation should contain some criteria pertaining to the physical characteristics of textbooks, such as cover design, text layout, size of print, printing quality, paper quality, book weight and durability.

iii. Content criterion: Textbooks should be chosen to advance the educational objectives of schools, fit the needs of students and contribute towards continuity and integration of the curriculum. A good textbook should lead teachers and students beyond the textbook into a wide variety of other materials and experiences. In addition, the text (content) should be accurate and appropriate, and regularly revised to meet changing conditions.

iv. Instruction criterion: A good textbook complements a teacher's classroom instruction. Thus ancillary materials such as instructional handbooks, classroom activities guides, workbooks, audio/visual components, and assessment packages should be carefully designed and provided to teachers along with the textbook.

Many schools in Taiwan create their own textbook selection checklists based on the above criteria (or similar criteria suggested by other scholars), but almost none of these checklists weigh the criteria differently, simply giving the same importance to all criteria. Such over-simplified checklists often lead to a misunderstanding of the total scores formulated by teachers, which not only confuses schools, but also perplexes publishing companies. Muther (1985) 
warns that without appropriate textbook selection training and tools, teachers may mostly focus evaluation on pretty pictures, amusing agents, seducing sales presentations, manuals, and free materials, but not the alignment of contents to their teaching goals. Hence, this research is aimed to develop a weighting system for the selection criteria, and to build a perceptual map of the major publishers in respect to the relevant criteria.

\section{Methodology}

A questionnaire titled "Elementary School Teacher Textbook Selection Survey" was administered to 504 teachers in 72 elementary schools. The schools were selected at random from a list of 2547 schools across Taiwan published by the Taiwan MOE. We asked each school to administer questionnaires to one teacher (committee member) from each of the seven curriculum items defined by the MOE. Only responses received within six weeks of the initial mailing were included in the study. Of the 332 questionnaires returned within six weeks, only 294 were valid for correspondence analysis. Moreover, since AHP requires that the decision maker remain consistent in making pair-wise comparisons among numerous decision criteria, we further conducted a consistency assessment, with only 134 of the 294 valid questionnaires passing this assessment. All of these 134 questionnaires were examined using AHP.

We solicited survey responses in various forms. The first part of the questionnaire requested the respondent's biographical information, including gender, teaching experience, teaching subjects, and the geographic location of their school. These data then served as independent variables in t-test and ANOVA to decide whether the teacher's background would significantly affect their textbook selection criteria.

Since we used AHP as the major method for weighting textbook selection criteria, the second section of questions were pair-wise in nature. This design was based on Saaty's (1994) theory that humans are better able to quantify their preferences when faced with just two items to consider, than when attempting to assign relative preference values to three or more items simultaneously. Teachers were asked to compare each criterion to all the others, assigning a relative importance rating on a scale ranging from 1-9. A rating of 1 indicates that the two criteria are equally important, and a rating of 9 indicates that a given criterion is much more important than the other one, and vice versa. The ratings were then assembled into a positive reciprocal matrix, where the rating was transformed into weights. Questions in the third part of the questionnaire were used to determine market position through the carrying out of correspondence analysis. Since correspondence analysis needs categorical data as input, the questions regarding market position were check-off in nature. Correspondence analysis is a multivariate technique for converting frequency tables into graphical maps in which rows and columns are depicted as points. Questionnaire respondents were asked to make a checkmark next to each publisher they deemed meets the specified criterion. The 16 factors adopted for the correspondence analysis were the same sub-criteria used in AHP: integration, multiple objectives, accuracy, appropriateness, activity design, assessment, support resource, instructional methodology, cover and text layout, durability, printing quality, paper quality, publisher reputation, marketing strategies, customer services, and price.

\section{Research Findings}

Table 1 presents descriptive statistics for the valid sample. First of all, there are clearly more females $(60 \%)$ than males $(40 \%)$ serving on the elementary school textbook selection committees. Since we asked the randomly selected schools to administer the questionnaire to one committee member per curriculum item, the distribution of the curriculum items is quite similar, each containing around $14 \%$ of the sample, and indicating that the various teaching specializations are well represented. Moreover, it should be noted that the sample's distribution as regards geographic location $-17 \%$ of the schools are located in urban areas, while $62 \%$ are in suburban areas, and $21 \%$ are in rural areas - is somewhat different from the parameter $(15 \%, 51 \%, 34 \%$ for urban, suburban, and rural respectively). The shortage of rural schools in the sample can be attributed to the extremely small size of some of these schools, resulting in their textbook selection committee being too small to include representatives from all of the seven curriculum items.

In the AHP structure in Figure 1, the highest level is the main objective of this research: selection of a good textbook. The second level consists of the major criteria for textbook selection: content, instruction, form and publisher. The third level consists of the sub-criteria for each of the four major criteria.

The results of the AHP analysis (see Figure 2) revealed the relative weight of each criterion: content, 38.8\%; instructional activities, $37.3 \%$; form, $12.3 \%$; and publisher, $11.7 \%$. Moreover, we calculated the relative importance of all the sub-criteria, and found that content accuracy (15.1\%) and instruction methodology (13.1\%) were perceived to be the most important sub-criteria for textbook selection, while the two least emphasized were paper quality $(2.1 \%)$ and marketing system $(1.5 \%)$. 
One-way analysis of variance (ANOVA) and a t-test were used to examine the variance amongst teachers of different backgrounds with respect to the emphasis they gave to each of the four criteria of textbook selection. The results suggest that school location has a significant $(p=.05)$ impact on teacher perceptions. Those teaching in urban areas appear to value the content criterion more than do teachers from schools in suburban and rural areas. Teachers in suburban areas give more importance to the instruction criterion than do their urban counterparts, while teachers from rural areas score form higher than do teachers from urban areas, and they also score publisher criteria higher than their suburban counterparts.

Correspondence analysis was used to illustrate how publishers differ with regards to selection criteria and curriculum items. Figures 3 shows the relationships between the four textbook selection criteria and the seven curriculum items for the three major publishers, and indicate a number of possible differences between how teachers perceive a publisher and the publisher's actual market position. Recognition of the differences illustrated in Figures 3 can help teachers select textbooks that better suit their needs, and can help publishers identify directions for market repositioning. The closer a criterion or subject is to a publisher on the map, the stronger the perceived identification of that publisher with that criterion or subject. Figure 3 suggests that teachers perceived PA as a stronger publisher in the form and publisher criteria, while PB and PC had better scores in the criteria of instruction and content.

A second correspondence analysis, shown in Figure 4, displays the relative positions of the seven curriculum items and the three major publishers. The map suggests that teachers perceived PA to be strongly associated with integrated activities and language arts. Teachers find PB more attractive in the subjects of science and technology, and health and physical education. PC scored strongest in social studies, arts and humanities, and mathematics.

\section{Conclusion}

This research was carried out in order to identify the major criteria used by elementary school teachers in selecting textbooks, and to weigh the importance of each criterion. Also, this research aimed to investigate the market positions of the three major textbook publishers in Taiwan as perceived by elementary school teachers with regard to curriculum items and textbook selection criteria.

The results of AHP show that teachers gave more importance to the content and instruction criteria, and give less importance to the form and publisher criteria. In addition, content accuracy, instruction methodology, content appropriateness, and class activities were perceived by teachers to be the four most important sub-criteria. These findings not only provide teachers with a set of criteria on which to found their textbook selections, but also offer publishers information which can be used to design their products to suit the major criteria and standards identified by their main customers.

The ANOVA results reveal that teachers from urban schools give more emphasis to the content criteria than do their suburban and rural counterparts, while teachers from rural areas put more emphasis on the publisher criteria. Moreover, suburban school teachers emphasize instruction criteria more than urban school teachers do, and rural school teachers give more importance to form than do their suburban counterparts. Since teachers from different school locations emphasize very different criteria when selecting textbooks, publishers should keep in mind each group's tendency when developing their products, and should also consider the use of several different product lines, instead of one unified line, as a way of enhancing their marketing efficiency.

According to the results of the correspondence analyses, teachers perceived PA to be strongly associated with integrated activities and language arts. PB was more attractive to teachers in science and technology, and health and physical education. PC scored strongest in social studies, arts and humanities, and mathematics. The results of this study provide teachers in every subject with specific research-based guidelines for textbook selection.

\section{Reference}

Deng, J. W. (2003). An analysis on textbook liberalization and its problems. Curriculum and instruction quarterly, 6 (1), 27-42

Farr, R., Tulley, M., \& Powell, D. (1987). The evaluation and selection of basal readers. The elementary school journal, 87, 267-281. http://dx.doi.org/10.10.1086/461494

Lai, K. C. (1996). Weighting textbook selection criteria: An AHP approach. Nantou, Taiwan: Taiwan Provincial Department of Education.

Lan, S. D. (2001). A review of the textbook publishing and auditing system at the compulsory educational level in Taiwan [in Chinese]. News bulletin of the national institute for compilation and translation, 14 (2), 2-10

Muther, C. (1985). What every textbook evaluator should know. Educational leadership, 42(7), 4-8 
Oh, Y. S. (1996). Criteria for elementary school textbook evaluation [in Chinese]. Taipei, Taiwan: Association for the Research and Development of Teaching Materials.

Reynolds, J. C. (1979). Controversy involving selection of science and humanities textbooks. Education, 99(3), $250-256$

Saaty, T. L., \& Vargas, L. G. (1994). Decision making in economic, political, social and technological environments with analytic hierarchy process. Pittsburgh: University of Pittsburgh.

Stein, M., Stuen, C., Carnine, D., \& Long, R. M. (2001). Textbook evaluation and adoption. Reading \& writing quarterly 17(1), 5-23. http://dx.doi.org/10.1080/105735601455710

Shannon, P. (1982). Some subjective reasons for teachers reliance on commercial reading materials. The reading teacher, 884-889

Tully, M., \& Farr, R. (1990). Textbooks and schooling in the United States. in D. L. Elliott, and A. Woodward, (Eds.), The $89^{\text {th }}$ Yearbook of the National Society for Study in Education, Part I, National Society for Study in Education, 162-177

Zhao, L. Y. (1994). The current issues and future developments of lifting the ban on textbook publishing [in Chinese]. Journal of education research, 42, 7-13

Table 1. Descriptive Statistics of Sample

\begin{tabular}{llcc}
\hline Variable & Classification & Frequency & Percent \\
\hline \multirow{2}{*}{ Gender } & Male & 117 & 39.8 \\
& Female & 177 & 60.2 \\
\hline \multirow{5}{*}{ Lubjects } & Language Arts & 42 & 14.3 \\
& Mathematics & 39 & 13.3 \\
& Social Studies & 43 & 14.7 \\
& Science and Technology & 42 & 14.3 \\
& Arts and Humanities & 43 & 14.6 \\
& Health and Phys. Ed. & 40 & 13.6 \\
& Integrated Activities & 45 & 15.3 \\
\hline \multirow{3}{*}{ Geographic Location } & Urban & 50 & 17.0 \\
& Suburban & 181 & 61.6 \\
& Rural & 63 & 21.4 \\
\hline
\end{tabular}


Table 2. ANOVA of school location on criteria

\begin{tabular}{|c|c|c|c|c|c|c|}
\hline Criterion & Location & $\mathrm{N}(134)$ & Mean & $\mathrm{SD}$ & $\mathrm{F}$ & Post-hoc \\
\hline \multirow{3}{*}{ Content } & Urban & 20 & .49 & .14 & $11.272 * *$ & Urban $>$ Suburban \\
\hline & Suburban & 81 & .38 & .11 & & Urban > Rural \\
\hline & Rural & 33 & .33 & .12 & & \\
\hline \multirow{3}{*}{ Instruction } & Urban & 20 & .30 & .13 & $3.419^{*}$ & Suburban $>$ Urban \\
\hline & Suburban & 81 & .37 & .12 & & \\
\hline & Rural & 33 & .35 & .12 & & \\
\hline \multirow{3}{*}{ Form } & Urban & 20 & .10 & .05 & $3.412^{*}$ & Rural > Urban \\
\hline & Suburban & 81 & .13 & .08 & & \\
\hline & Rural & 33 & .16 & .10 & & \\
\hline \multirow{3}{*}{ Publisher } & Urban & 20 & .11 & .05 & $4.007 * *$ & Rural $>$ Suburban \\
\hline & Suburban & 81 & .12 & .12 & & Rural > Urban \\
\hline & Rural & 33 & .16 & .16 & & \\
\hline
\end{tabular}

$* \mathrm{P}<.05, \quad * * \mathrm{P}<.01$

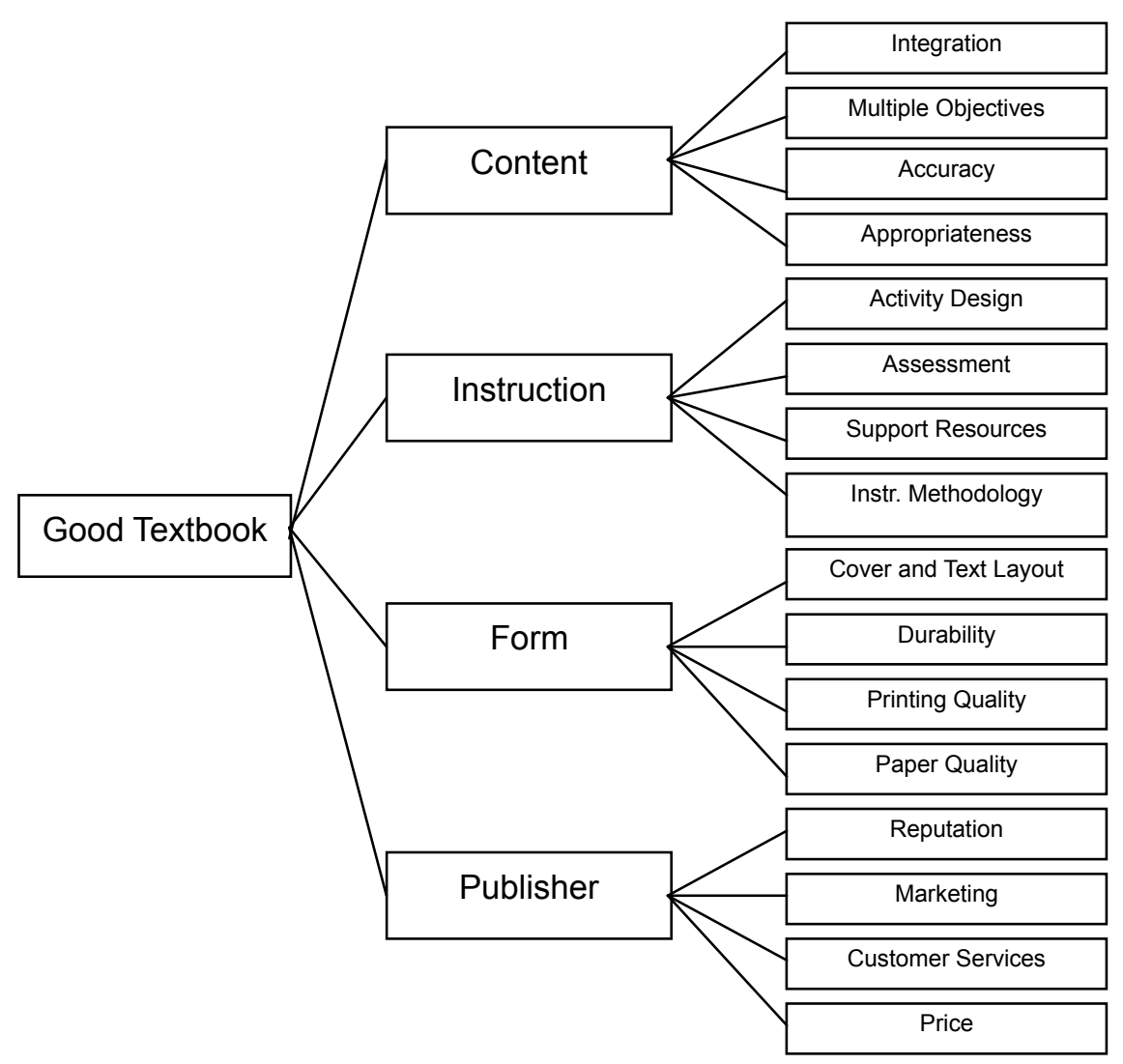

Figure 1. AHP Structure 


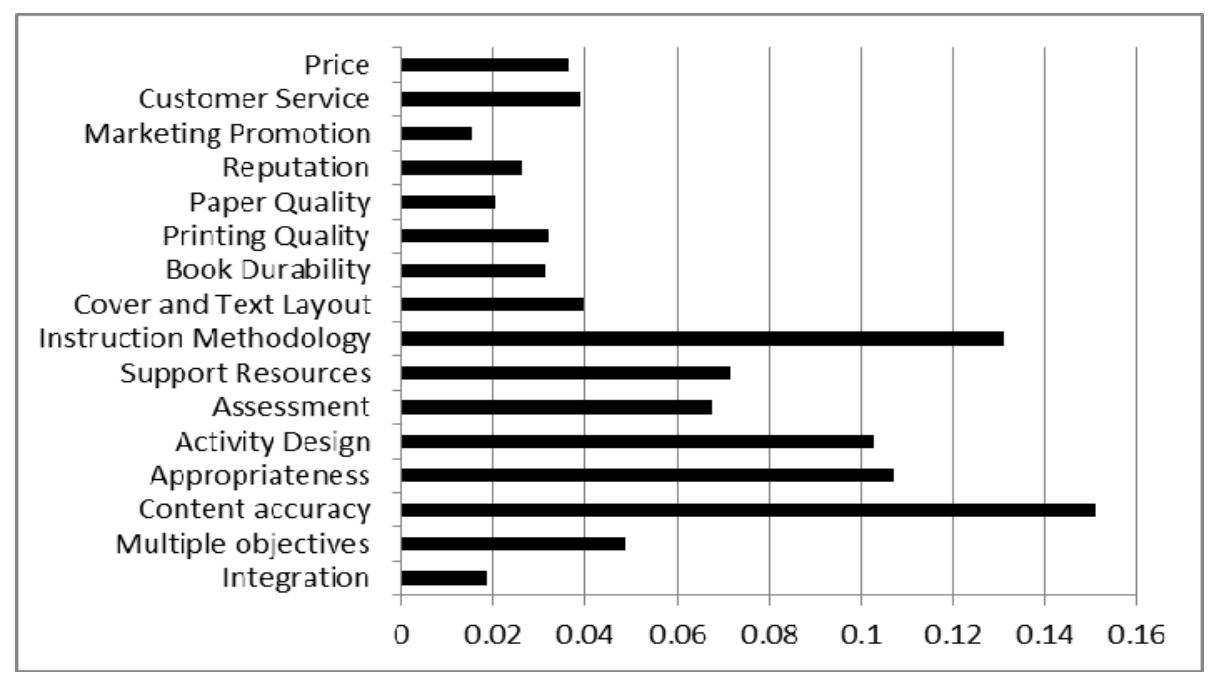

Figure 2. Relative weight of textbook selection factors

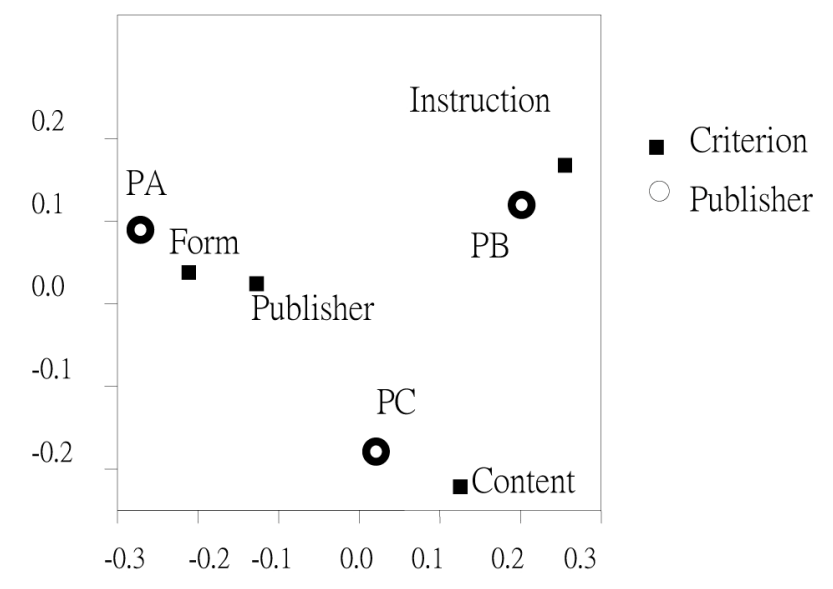

Figure 3. Perceptual map of publishers and criteria

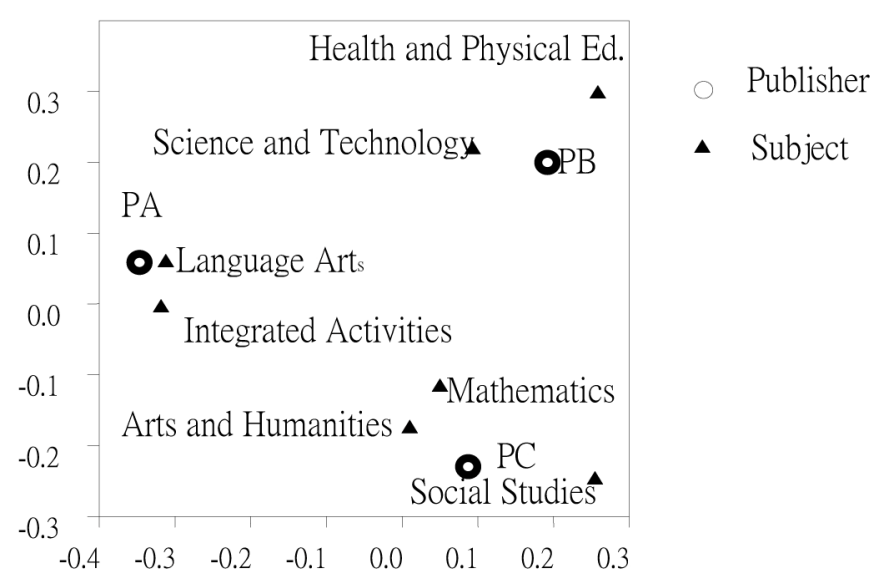

Figure 4. Perceptual map of publishers and curriculum criteria 